\title{
Evaluating the Materials Used for Hydrogen Production Based on Photoelectrochemical Technology
}

\author{
Mohammdreza Nazemzadegan and Roghayeh Ghasempour*
}

\author{
Department of Renewable Energies and Environmental, Faculty of New Sciences and Technologies, University of Tehran, Tehran, Iran
}

\begin{abstract}
Hydrogen as a $\mathrm{CO}_{2}$-free fuel has been considered as a serious alternative for problematic fossil fuels in recent decades Photoelectrochemical (PEC) water splitting is a developing solar-based technology for hydrogen production. In this study, some possible options for upgrading this technology from R\&D stage to prototype stage through a material selection approach is investigated. For these purpose, TOPSIS algorithm through a multi criteria decision making (MCDM) approach was utilized for evaluating different (PEC)-based hydrogen production materials. $\mathrm{TiO}_{2}, \mathrm{WO}_{3}$ and $\mathrm{BiVO}_{4}$ as three semiconductors known for their PEC application, were selected as alternatives in this decision-making study. After defining a set of criteria, which were assessed based on similar studies and experts' visions, a group of ten PEC-experts including university professors and $\mathrm{PhD}$ students were asked to fill the questionnaires. The eight criteria considered in this study are include "Study Cost", "Synthesis Simplicity", "Facility \& Availability", "Deposition capability on TCO", "Modifiability", "Commercialization in $\mathrm{H}_{2}$ production", "Physical and Chemical Durability" and "Eco-friendly Fabrication". The final TOPSIS results indicates that $\mathrm{TiO}_{2}$ is selected as the best semiconductor for further investments in order to upgrade the PEC-based hydrogen production technology from R\&D level to prototype stage. O2019. CBIORE-IJRED. All rights reserved
\end{abstract}

Keywords: MCDM, TOPSIS, Hydrogen generation, PEC, Semiconductor.

Article History: Received: Feb 12, 2019; Revised: April 18, 2019; Accepted: April 25, 2019; Available online: July 15, 2019

How to Cite This Article: Nazemzadegan, M. and Ghasempour, R. (2019) Evaluating the Materials Used for Hydrogen Production Based on Photoelectrochemical Technology. Int. Journal of Renewable Energy Development, 8(2), 169-178.

https://doi.org/10.14710/ijred.8.2.169-178

\section{Introduction}

As the most important future energy carrier, hydrogen $\left(\mathrm{H}_{2}\right)$ has drawn a considerable attention and is created a vital demand for $\mathrm{H}_{2}$ production technology investment. Hydrogen can be used as fuel for engines and fuel cells to increase efficiency and decrease the environmental issues (Muppala, Manickam, \& Dinkelacker, 2015; Talukdar, 2017). There are several approaches for producing hydrogen (Amekan et al. 2018; Kanoglu, Yilmaz, \& Abusoglu, 2016). Due to advantages of renewable energy systems especially lower carbon dioxide emission (Bardineh et al. 2018), these types of technologies is more preferable for producing hydrogen. The Photoelectrochemical (PEC) method is one of the cleanest developing technologies which is capable of producing $\mathrm{H}_{2}$ gas by utilizing water (Ali et al. 2018; Chen et al. 2013; Chen et al. 2018). Apart from that, this technology has applications in water treatment industries, making it a promising technology for the near future (Mills \& Le Hunte, 1997).

The PEC technology is based on utilizing a semiconductive material to absorb sun-light and use it as the driving force of a number of reactions, including water splitting and degradation of some water organic pollutants. In these technologies, sun-light produces pair electron/hole in the semiconductor causing an oxidationreduction reaction from water to obtain hydrogen and oxygen separately. A schematic description of a photoelectrode-based PEC devise is illustrated in Figure 1 .

Being in the R\&D stage, PEC has yet to find a way to produce hydrogen in large scale. Additionally, in comparison with current hydrogen production techniques, the efficiency of PEC method is insignificant. However, among various hydrogen production technologies, PEC is considered as one of the cleanest, as it only relays on solar energy and water molecules to produce hydrogen. Besides the improvement of its efficiency has been remarkable in the past decade. Therefore, this technology is considered as an important option for replacing troublesome fossil fuels in hydrogen system in near future.

International organizations of energy have recognized the importance of PEC technology in the future of hydrogen production technologies. According to the renewable hydrogen production pathways presented by International Renewable Energy Agency (IRENA) (IRENA, 2018), solar based hydrogen production technologies such as PEC are in the applied research stage of the pathway. Figure 2 shows the current maturity levels of renewable hydrogen production technologies. The U.S. Department of Energy (DOE) has published a list of

\footnotetext{
*Corresponding Author: ghasempour.r@ut.ac.ir
} 
technical targets for PEC-based hydrogen production technologies (described later in "Literature review" section). In This list two type of PEC technology are considered: 1) Photo-electrode systems and 2) photo- catalysis systems (U.S. Department of Energy [DOE], 2018).

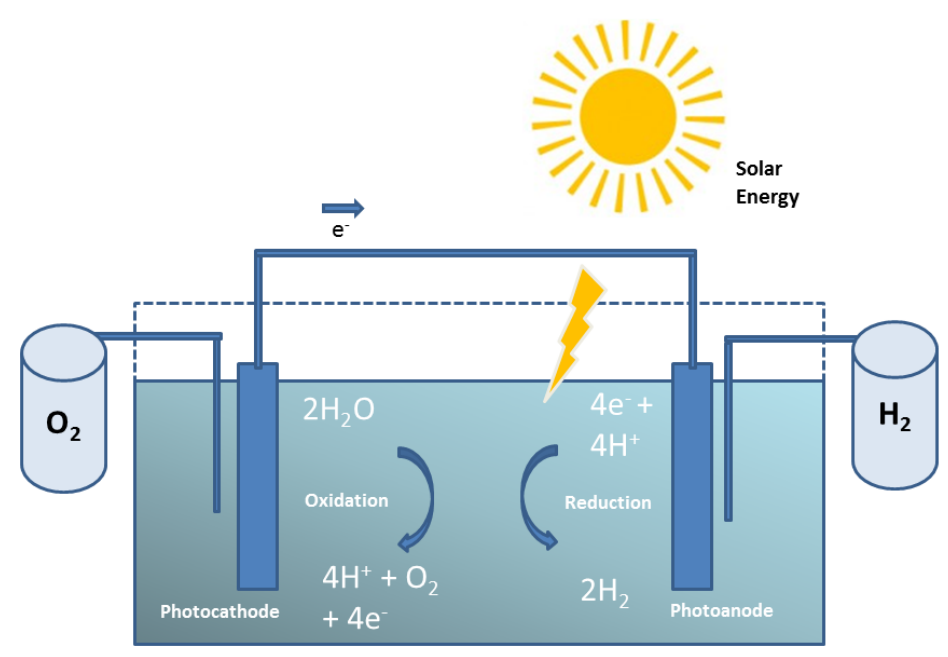

Figure 1. A schematic description of a photoelectrode-based PEC devise

Therefore, for PEC-based technologies, which are in the $\mathrm{R} \& \mathrm{D}$ phase of $\mathrm{H}_{2}$ production, one of the essential questions is, what material should be invested on, to reach the prototype level and in this regard increase the chance of its commercialization in the shortest time. To find the answer, considering the advantages and disadvantages of materials to each other in various areas, it is needed to utilize a decision-making process. Among the materials used in renewable hydrogen production technologies, ntype semiconductor materials such as $\mathrm{TiO}_{2}, \mathrm{WO}_{3}, \mathrm{Fe}_{2} \mathrm{O}_{3}$ and $\mathrm{BiVO}_{4}$ are used for PEC technology due to their suitable physical and chemical properties such as suitable band gap, however, each semiconductor has advantages and disadvantages over others. Low light-absorption efficiency, electrical and quantum efficiency are some technical features of semiconductors, while factors such as availability, modifiability, research and experiment costs, safety and eco-friendliness all are features which affects the capability of a material to reach the prototype level in the fastest and safest way. The variation of these criteria brings the necessity of utilizing a decision-making procedure.

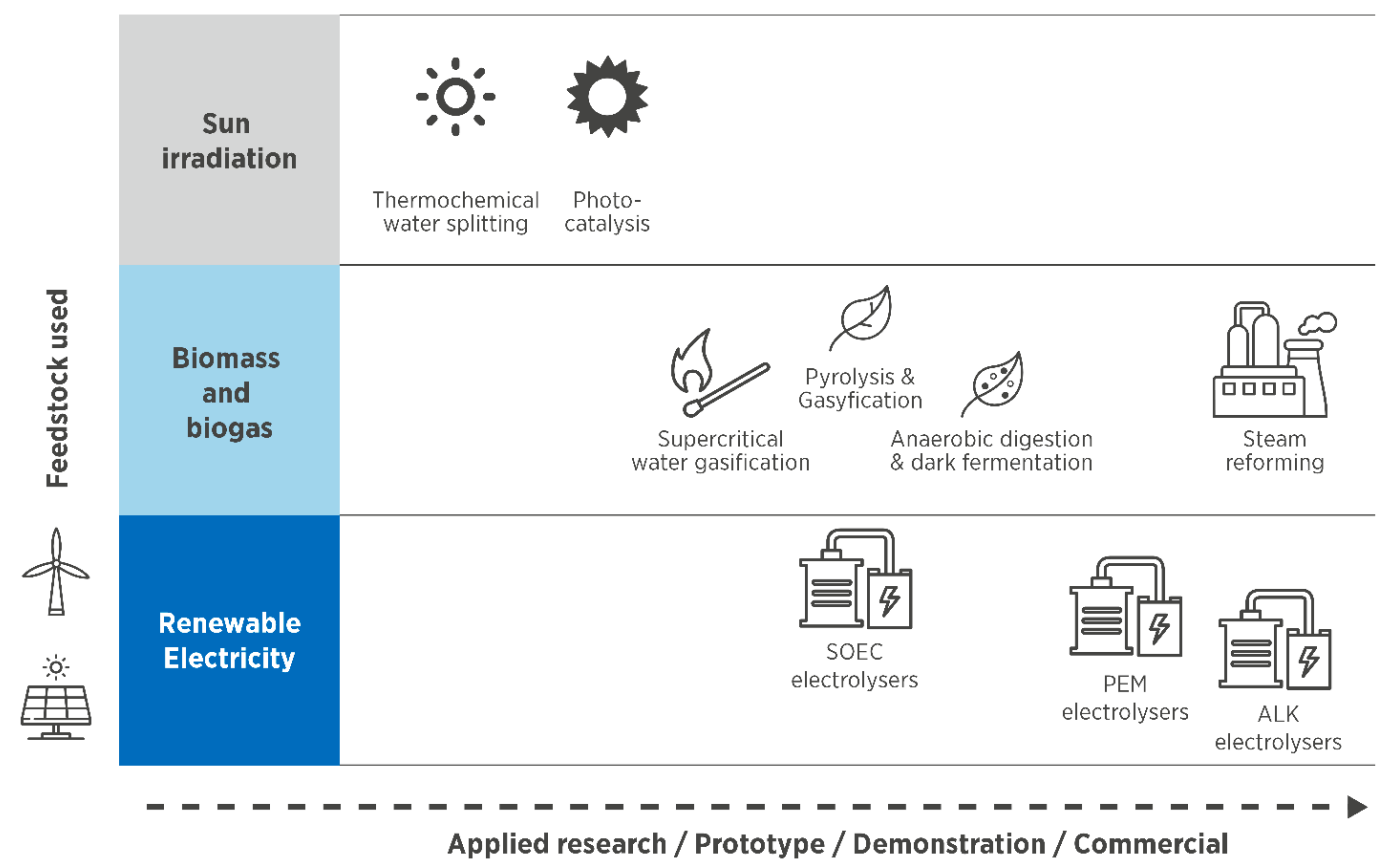

Figure 2. Current levels of maturity for renewable hydrogen production technologies (IRENA, 2018) 
The most suitable semiconductor for PEC technology can be decided through different methods. Though for all of these methods, the first and one of the most important steps is to define the genuine criteria and to classify their importance properly. Economic issues, facility, environmental considerations, availability and commercialization capability are some of the most frequent criteria in $R \& D$ project evaluation and technology selection decision makings (Vafaeipour et al. 2014; Wang et al. 2015; Watson \& Hudson, 2015; Zhao \& $\mathrm{Li}, 2015$ ).

In this study, for the first time, the comparison is carried out between $\mathrm{TiO} 2$ and WO3, as the two well-known semiconductors, and $\mathrm{BiVO} 4$, as a semiconductor that is attracting a growing attention, through a multi-criteria decision making (MCDM) approach. In this research, first a set of criteria are defined and then evaluated by PEC experts via a designed questionnaire. The criteria include "Study Cost", "Synthesis Simplicity", "Facility \& Availability", "Deposition capability on TCO ", "Modifiability", "Commercialization in $\mathrm{H}_{2}$ production", "Physical and Chemical Durability" and "Eco-friendly Fabrication". Finally, by utilizing TOPSIS algorithm the best semiconductor is selected. The goal of this work is to propose a new approach for deciding about available alternatives in progressing a technology. Here the case is to find the best semiconductor in order to help the PEC technology (which is in the R\&D level) reach to its next step (prototype level) considering the aforementioned criteria.

\section{Literature Review}

Excessive use of fossil fuels has caused an increasing rate of $\mathrm{CO}_{2}$ emission in recent years. On the basis of $\mathrm{BP}$ report (BP, 2018), the emission of carbon dioxide has noticeably increased from 18364.1 Mt in 1980 to approximately $33444 \mathrm{Mt}$ in 2017. The trend of carbon dioxide emission during the mentioned years is represented in Figure 3.

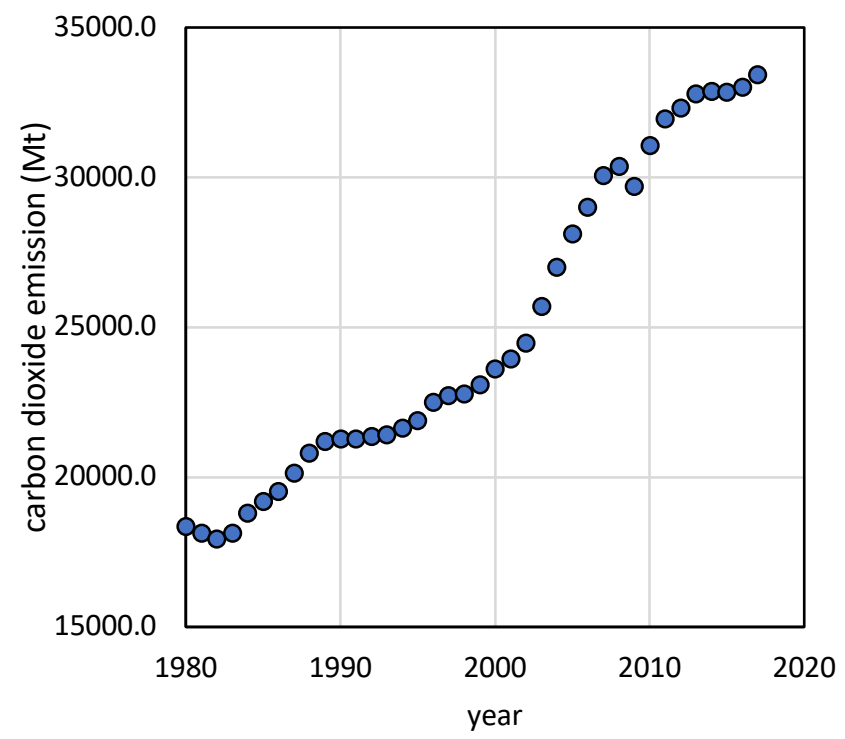

Figure 3.Carbon dioxide emission in recent years (Bp, 2018)

Solving the CO2 emission problem of fossil fuels requires either an improvement in their efficiencies (Ahmadi et al. 2018a; Ramezanizadeh et al. 2018a) or replacing them with other energy resources (Ghoujdi, 2018, Ahmadi et al. 2018b; Ahmadi et al. 2018c; Ahmadi et al 2018d). One of the fossil fuel applications which can be replaced by renewable energies is hydrogen production (Ahmadi et al. 2018d; Amekan et al. 2018; Handayani \& Ariyanti, 2012; Madvar et al., 2018; Menges \& Pfaffenberger, 2015; Kaloi 2017). There are various ways and diverse energy sources to produce this gas. Fossil fuels and a wide range of renewable energies can be utilized in $\mathrm{H} 2$ production processes. Currently, the main source used for hydrogen production is natural gas, which has $48 \%$ share; while applying electrolysis has the lowest share with $4 \%$. The shares of each sources in produced hydrogen is shown in Figure 4.

As mentioned earlier, one of the most attractive technologies of hydrogen industries is PEC technology. PEC is known as a solar-based technology which directly uses the abundant energy of sun. DOE considers PEC technology as one of the elements of their long-term program in hydrogen production prospect (U.S. Department of Energy [DOE], 2017). Figure 5 shows a broad view of this prospect. As it is illustrated in this portfolio, PEC technology is planned to be one of central sources of hydrogen along some technologies such as natural gas reforming, gasification and electrolysis. The plant capacity targeted for the PEC technology is in scale of generating $50000 \mathrm{~kg}$ hydrogen per day. In this program the timeline is divided into near-term, mid-term and longterm periods and PEC belongs to the solar pathways which is anticipated for the long-term program.

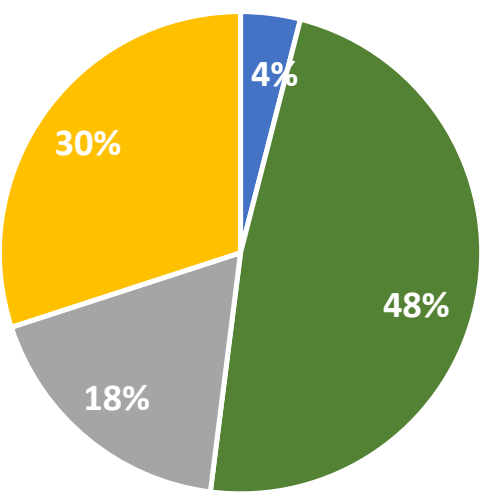

- Electrolysis | Natural Gas | Coal | Oil

Figure 4. Share of various sources in produced hydrogen

(IRENA, 2018)

DOE has set targets for PEC technology in $\mathrm{H} 2$ production. The targets are generally about three main topics: 1 - the production cost, 2 - The technology efficiency and 3- The replace time of PEC parts. The two considered types of PEC technology in this report include photoelectrode-based and photocatalyst-based PEC devises. The five targets of DOE for photoelectrode system are as follows:

1- Cost of PEC-based generated hydrogen

2- Concentrator and PEC receiver capital cost

3- Annual cost of electrode

4- Solar to hydrogen energy conversion

5- Hydrogen production rate of 1-sun radiation 
These targets are set for years 2011, 2015 and 2020 in order to be a set point especially for the long-term researches in PEC field. While there is also an ultimate target presented by DOE which is targeting the market competitiveness ([DOE], 2018).

DOE's Fuel cell technologies office has described their plan for diverse hydrogen production technologies in their multi-year research, development and demonstration plan. As it is reported, following timeline for PEC technology development is stablished (U.S. Department of Energy [DOE], 2015):

1- Establishing standards for all aspects of the PEC technology.

2- Improving durability in PEC devises with highefficient materials.

3- Improving efficiency in PEC devises with stable materials.

4- Discovering stable and highly efficient materials for PEC uses.

5- Developing cost-effective PEC-based watersplitting reactors.

PEC as a semiconductor-based hydrogen production technology, requires developments in materials to pass the early stages of developments (U.S. Department of Energy [DOE], 2015). There are numerous semiconductors which can be utilized as the main material of the PEC technology. DOE has divided current material systems for PEC photoelectrodes into three categories based on their characteristics and research challenges:

1- High efficient, relatively high cost, limited lifetimes (e.g., Group III-V crystalline materials)

2- Lower efficiency, relatively lower cost, stable (e.g., metal- and mixed-metal oxide thin films)

3- Hybrid and multi-junction systems

$\mathrm{TiO}_{2}, \mathrm{WO}_{3}, \mathrm{Fe}_{2} \mathrm{O}_{3}, \mathrm{ZnO}_{2}$ and $\mathrm{BiVO}_{4}$ are some of these alternatives all belongs to the second group. Materials of the second group due to their high stability and low cost, are more considerable option for further development. These semiconductors are developing and modifying through years and their cost, performance and durability are improving consistently. Metal and non-metal dopants, graphene, co-catalysts and variety of deposition methods are some means to enhance the performance and endurance of PEC photoelectrodes. (Abe, 2011; Daghrir, Drogui, \& Robert, 2013; Madhusudan et al 2013; Moniz, 2015; Ni et al. 2007; Zaleska, 2008).

However, in order to meet the objectives stablished by DOE in the shortest time, it is necessary to concentrate on a single material and invest all the time, money and energy assigned for the development project, on it. In this process the most important step is to select the best material for further investigation and investment. In this regard, the materials should be evaluated and a decisionmaking method should be utilized for the technology selection.

In order to find the best options, decision making algorithms have been widely used to find technology alternatives (Ghasempour et al. 2019). For example, Chang, et al (1994) have applied a fuzzy MCDM to select a strategy for technology transfer in biotechnology field. A technology selection algorithm using Data Envelopment Analysis (DEA) is proposed by Khouja to help potential buyers to choose a technology. It is a two phases algorithm which first identify technologies which matches vendors specifications and then the technology is selected using a multi criteria decision making model (Khouja, 1995). Using a strategic scorecard by Xia, et al is another example of decision-making application in the technology selection (Xia et al. 2017). Nazemzadegan et al (2017), compared Fuzzy, Linmap and TOPSIS decision making algorithms to find the best performance condition of a dish-Stirling engine in a multi-objective optimization program.

Research and Development (R\&D) evaluation is also an example of employing decision making in technology selection. Eilat, et al (2008) through a multi-criteria approach have used the scorecard method alongside DEA to evaluate $R \& D$ projects. The study is useful in different life time of projects including the proposal step, in which the base and materials of the project should be decided. R\&D evolution methods are divided into two main categories: 1- Weighting \& Ranking methods and 2Benefit-contribution methods (Poh, Ang, \& Bai, 2001). The approach of the current study is through the Weighting \& Ranking methods, as it is based on normalized weighted scores.

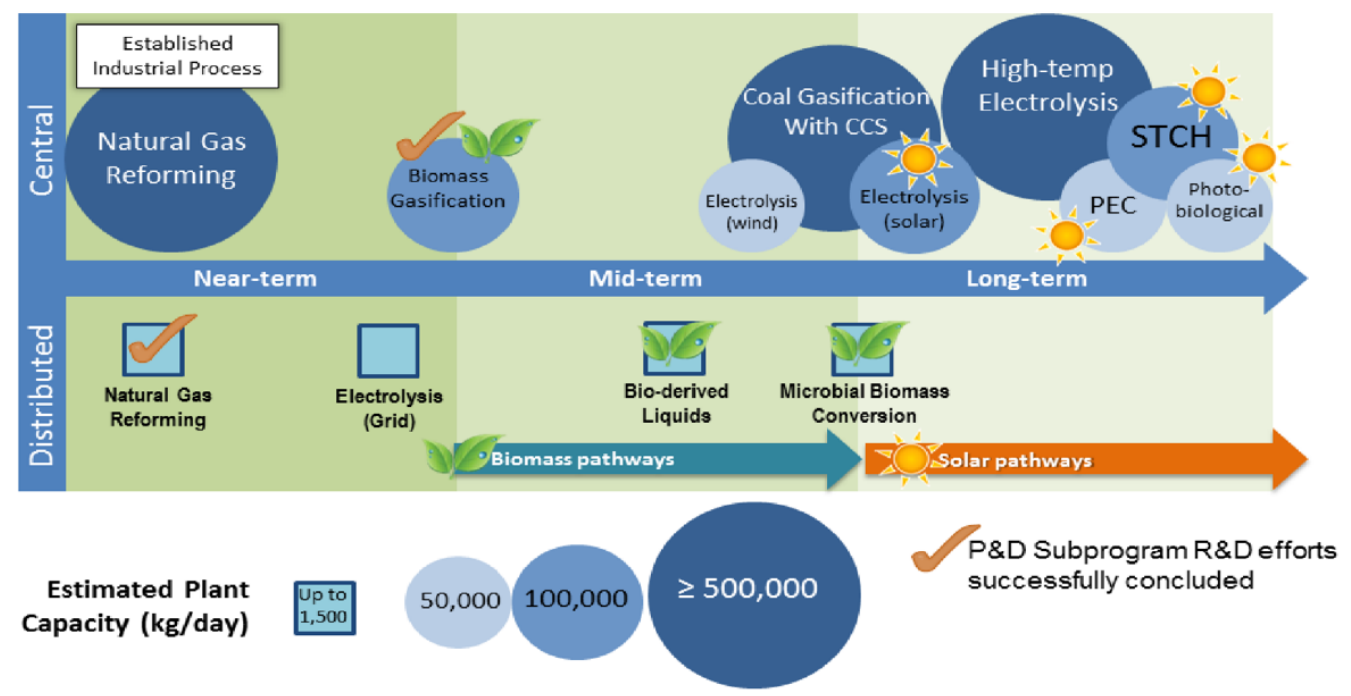

Figure 5. Broad hydrogen production prospect ( U.S. Department of Energy [DOE], 2017) 


\section{Important Criteria affecting the PEC material selection}

To start this decision-making procedure, a set of criteria needs to be arranged. Economic and environmental criteria are some frequent criteria used in many technology-based decision makings (Vafaeipour et al., 2014; Wang et al., 2015; Watson \& Hudson, 2015; Zhao $\& \mathrm{Li}, 2015)$. In addition to these criteria, there are criteria which usually are applied for R\&D evaluation case studies. They include complexity, availability, growth potential, customer potential, etc. which all are factors for evaluating a project proposal attractiveness (Eilat et al., 2008; Victório, Costa, \& Souza, 2015; Wang \& Tang, 2015). Eilat et al, introduced their criteria in diverse perspectives including financial, customer, internal-business, learning $\&$ growth, uncertainty and resources (Eilat et al., 2008).

The criteria stablished in this study are generally a reflection of the photoelectrode production process. Therefore, photoelectrode as a PEC technology test sample, reflects the performance of the hydrogen generator final product. Similar to what it is reported in a PEC research proposal, through a photoelectrode preparation process there are steps can be sorted as follows:

- Gathering relevant information related to the process.

- Considering the location and facilitates needed for the process.

- Providing precursor and other synthesis materials.

- Semiconductor Synthesis process and Modification (in case of necessity)

- Deposition process (on a TCO substrate)

- Physical and chemical stability tests

- Performance tests.

In order to overcome any mentioned stage properly, an uncertain amount of time, money and energy is required to spend. These requirements are so detail that are almost impossible to measure. In addition, there are unmeasurable factors such as complexity of the process, availability of the materials \& facilitates and product modifiability. Considering commercialization potential and Safety \& Eco-friendly factor, which are two common criteria in R\&D evaluation, these are all examples that are heavily depends on the expert's experiments.

So far a set of criteria has been stablished to facilitate the decision making process in order to conclude a semiconductor for PEC-based hydrogen generation. In addition to the literature review results, the PEC experts' Idea also has been considered in the criteria selection. Finally, the resulted criteria are categorized as follows:

1- Study Cost

2- $\quad$ Synthesis Simplicity

3- $\quad$ Facility \& Availability

4- Deposition capability on TCO

5- Modifiability

6- Commercialization in $\mathrm{H} 2$ production

7- $\quad$ Physical and Chemical Durability

8- Eco-friendly Fabrication

"Study Cost" refers to all cost of research phase of the project to achieve a test sample for the semiconductor. The test samples of semiconductors utilizing in PEC technology usually are their photo-electrodes. This criterion is one of the most important items in deciding a research proposal. Study cost cannot be determined just by considering the price of precursor and synthesis materials. It is needed to predict up to the very last step of the synthesis and the tests to calculate the exact cost of the research, therefore a more practical approach to estimate the cost is to rely on experiences.

"Synthesis Simplicity" indicates the time, knowledge and experience needed for fabrication of the semiconductors' laboratory test samples. It is hard to predict how many hours a through experimental study will take, or how much literature should be investigated for a project or how much skill is needed to conduct the fabrication experiment; but on the other hand, it is possible to compare overall score of three different semiconductors in term of simplicity. 'Therefore, "Synthesis Simplicity" is one of the criteria of current study.

"Facility \& Availability" refers to all laboratory facilities and the semiconductors' synthesis materials availability. To compare the synthesis procedure of the three semiconductors' photoelectrodes, the facilities and materials availability are factors that affects greatly the possibility of the procedure accomplishment. It is important to consider these two factors in the research proposal preparation in order to avoid any interval during the procedure.

"Deposition capability on TCO" implies that how facile, fast and in how many methods the layer of each semiconductor can be deposited on a TCO substrate. This factor is one of the most important elements in fabricating a semiconductor photo-electrode

"Modifiability" criterion is about the capability of each semiconductor in getting improved by using any modification method, including doping, making complexes, using co-catalysts, changing the assembly, etc. The more a semiconductor is modifiable, the more reliable it is, as it is more possible to find a way to improve its performance.

As a criterion, "Commercialization in $\mathrm{H}_{2}$ production" is asking the experts that how many chances they predict for each semiconductor to get to the level of commercialization in the industry of $\mathrm{H}_{2}$ production.

Durability of the fabricated Photoelectrode is one of the items included in the DOE target for PEC-based hydrogen production technologies. This item is considered in this study by "Physical and Chemical Durability" criterion. This criterion refers to durability of the fabricated photo-electrode as the test sample.

"Eco-friendly Fabrication" not only aims the safety and environmental aspects of final produced photoelectrode as the hydrogen production device, but also involves the fabrication procedure such as toxicity of precursors and solutions utilized through the synthesis process.

Considered criteria are set based on similar R\&D evaluating and technology selection studies (Vafaeipour et al., 2014; S. H. Wang et al., 2015; Watson \& Hudson, 2015; Zhao \& Li, 2015) and all are assessed by three professionals in PEC field, before delivering questionnaires to the experts. The resultant score is normalized by TOPSIS method and after utilizing the decision-making algorithm, the best semiconductor is selected.

The overall procedure flowchart is illustrated in Figure 6. In the first step the importance weight of criteria is calculated based on experts' weight assessments. In the second step the normalized vector of alternatives is 
calculated. Utilizing the weight vector of criteria, the normalized weighted vector of alternatives is achieved. In the next step TOPSIS decision making algorithm is applied to the normalized and weighted scores and resulted to final scores for semiconductors.

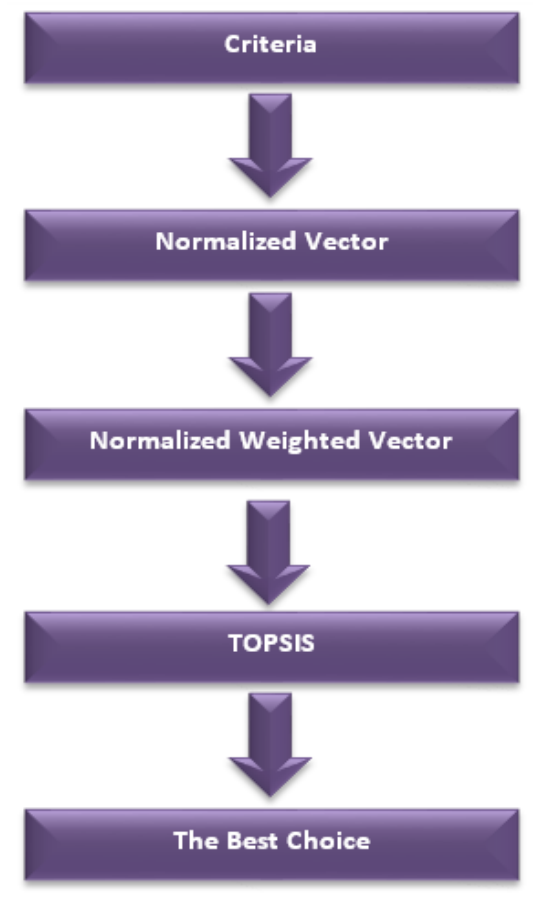

Figure 6. The decision making flow chart of current study

\section{TOPSIS Method}

The TOPSIS method, is a technique for ordering preferences based on similarity to the ideal solution. Some of the advantages of this method over other MCDM methods, such as ELECTRE, weighted product, and weighted sum, are its consistency and simplicity (El Amine et al 2014). TOPSIS also is known for its ability to consider a non-limited number of alternatives and criteria in the MCDM problems (Junior et al, 2014). By having these advantages TOPSIS has become one of the most regular MCDM methods (Tscheikner-gratl et al. 2017).

Utilizing an MCDM method, with $\mathrm{m}$ alternatives evaluated by $n$ criteria, the data matrix can be considered as a $n \times m$ matrix where $X_{i j}$ is the value for the $i^{\text {th }}$ alternative determined by the $j^{\text {th }}$ criterion.

In first step, the normalized value should be calculated as (Nazari, Aslani, \& Ghasempour, 2018):

$r_{i j}=\frac{X_{i j}}{\sqrt{\sum_{i=1}^{m} X_{i j}^{2}}} \quad i=1, \ldots, m ; j=1, \ldots, n$

To obtain the weighted normalized vector, the score of each alternative should be multiplied by its weight as follows:

$v_{i j}=w_{j} r_{i j}$

Where, $w_{j}$ is the weight of $j^{\text {th }}$ criterion, resulted from dividing each criterion raw score to the linear average of all criteria's scores ( Nazari, Aslani, \& Ghasempour, 2018). For the $j^{\text {th }}$ criterion, $v_{j}^{*}$ and $v_{j}^{-}$represent the maximum and minimum weighted normalized values, respectively and are defined as:

$$
\begin{aligned}
& v_{j}^{*}=\left\{v_{1}^{*}, \ldots, v_{j}^{*}, \ldots, v_{n}^{*}\right\}=\left\{\max v_{i j}\right\} \\
& v_{j}^{-}=\left\{v_{1}^{-}, \ldots, v_{j}^{-}, \ldots, v_{n}^{-}\right\}=\left\{\min v_{i j}\right\}
\end{aligned}
$$

In next step, for the $i$ th alternative, the distance of each criterion from, $v_{j}^{*}$ and $v_{j}^{-}$, are calculated as ( Nazari et al 2018):

$S_{i}^{*}=\sqrt{\sum_{j=1}^{n}\left(v_{i j}-v_{j}^{*}\right)^{2}}, \quad i=1, \ldots, m$
$S_{i}^{-}=\sqrt{\sum_{j=1}^{n}\left(v_{i j}-v_{j}^{-}\right)^{2},} \quad i=1, \ldots, m$

Finally, by obtaining factors of $S_{j}^{*}$ and $S_{j}^{-}$, for TOPSIS decision making method a factor of $C_{i}^{*}$ can be defined as (Nazari 2018):

$C_{i}^{*}=\frac{S_{i}^{-}}{S_{i}^{-}+S_{i}^{*}}$

Which the maximum $C_{i}^{*}$ presents the best option based on TOPSIS method ( Nazari et al 2018).

\section{Results and Discussion}

In order to evaluate the criteria, ten experts, including seven university professors and three $\mathrm{PhD}$ students from University of Tehran and Sharif University of technology, Iran, were surveyed. The experts were chosen based on being familiar with PEC-based hydrogen production and having experience in working with $\mathrm{TiO}_{2}, \mathrm{WO}_{3}$ and $\mathrm{BiVO}_{4}$. Eighty percent of respondents participated in this survey have more than two years' experience in the PEC field and half of them has more than five years' experience in this field.

Table 1 shows the normalized criteria scores, resulted from the rating that experts have given to each criterion. The raw scores which are inserted in the score sheets have been in a range of 1 to 7 evaluating each criterion importance from the least important to the most important. The normalized vector shown in Table 1 are based on dividing each criterion raw score to the linear average of all criteria scores.

Table 1.

Normalized criteria scores

\begin{tabular}{cc}
\hline Criteria & Normalized vector \\
\hline Study Cost & 0.123518 \\
Synthesis Simplicity & 0.121542 \\
Facility \& Availability & 0.11166 \\
Deposition capability on TCO & 0.082016 \\
Modifiability & 0.123518 \\
Commercialization in H2 & \\
Production & 0.143281 \\
Physical and Chemical Durability & 0.153162 \\
Eco-friendly Fabrication & 0.141304 \\
\hline
\end{tabular}

Based on the results of Table 1, experts believe that physical \& chemical durability is the most important factor to be considered for a semiconductor when utilizing in PEC technologies. Commercialization potential and environmental issues are scored as the second and third most important criteria in this material evaluation study.

Experts had also asked to attribute a score between 1 and 7 for each alternative in regards to each criterion. Therefore, by utilizing the criteria weighted scores (shown 
in Table 1) and based on the questionnaires scores for each alternative, the normalized vectors of alternatives are achieved. Table 2 shows the weighted normalized vectors of each alternative based on TOPSIS normalization formula represented in eq. 1

The decision-making procedure is between three semiconductors as three alternatives for utilizing in a PEC-based hydrogen production technology. These semiconductors all are familiar by their photo-active nature and their photocatalytic application is compared with each other. The selection of alternatives is based on the diverse advantage of each one that are explained below.

The first material is titanium dioxide $\left(\mathrm{TiO}_{2}\right)$, also known as titanium (IV) oxide, is a semiconductor capable of producing hydrogen gas from water. One of the main hindrances of $\mathrm{TiO} 2$ is that it can only activates by UV light. On the other hand, this semiconductor is known for its stability, it is a natural material and it has a wide range of applications, such as sunscreen and paint (Acar \& Dincer, 2016; Mills \& Le Hunte, 1997; Yourey, 2014).

The second option is tungsten trioxide $\left(\mathrm{WO}_{3}\right)$ or tungsten (VI) oxide, which is applied as a photosensitive semiconductor in water splitting technology. This photoactive material can absorb light in visible range, hence, it has drawn a considerable attention as one of the best photoelectrode candidates (Acar \& Dincer, 2016; Mills \& Le Hunte, 1997).
Bismuth Vanadate $\left(\mathrm{BiVO}_{4}\right)$ is the third alternative that similar to $\mathrm{WO}_{3}$, has a great potential of visible light absorption. Additionally, its durability and performance stability are remarkable. Other applications of this semiconductor are in fields of water treatment and paint industries (Acar \& Dincer, 2016; Mills \& Le Hunte, 1997; Venkatesan, Velumani, \& Kassiba, 2012).

As it is shown in Table 2, comparing the study cost of three semiconductors, experts have chosen $\mathrm{TiO}_{2}$ as the best option and $\mathrm{WO}_{3}$ as the second-best alternative. They also believe that $\mathrm{TiO}_{2}$ can be deposited on the TCO substrates (e.g. FTO or ITO) in more frequent and simpler methods in comparison with $\mathrm{BiVO} 4$ and $\mathrm{WO}_{3}$. It means that fabricating a $\mathrm{TiO} 2$ photoelectrode is more feasible than the other two options. $\mathrm{TiO}_{2}$ has also achieved the highest scores in terms of modifiability and durability, while in these two terms $\mathrm{BiVO}_{4}$ has even higher scores than $\mathrm{WO}_{3}$.

On the other hand, in term of simplicity of synthesis and also facility needed for this process, PEC experts believe that $\mathrm{WO}_{3}$ should be in the first place. $\mathrm{WO}_{3}$ has also chosen as the material with the eco-friendliest fabrication process among these three alternatives. That is while the $\mathrm{TiO}_{2}$ has less score than $\mathrm{BiVO}_{4}$ in this criterion, a result that can be attributed to the materials used in $\mathrm{TiO}_{2}$ synthesis, such as $\mathrm{HF}$ (Liu, Yu, \& Jaroniec, 2011).

Table 2.

Normalized and weighted vectors for each alternative

\begin{tabular}{cccc}
\hline Criteria & \multicolumn{3}{c}{ Semiconductors } \\
\cline { 2 - 3 } & TiO2 & BiVO4 & WO3 \\
\hline Study Cost & 0.641407 & 0.425354 & 0.638491 \\
Synthesis Simplicity & 0.632144 & 0.410631 & 0.657097 \\
Facility \& Availability & 0.653057 & 0.357706 & 0.667505 \\
Deposition capability on TCO & 0.674573 & 0.441613 & 0.591548 \\
Modifiability & 0.688369 & 0.53258 & 0.492449 \\
Commercialization in H2 Production & 0.693412 & 0.459842 & 0.55473 \\
Physical and Chemical Durability & 0.68693 & 0.521172 & 0.506465 \\
Eco-friendly Fabrication & 0.464125 & 0.547641 & 0.696188 \\
\hline
\end{tabular}

The next step is to select the maximum and minimum values in each criterion, (illustrated by $v_{j}^{*}$ and $\left.v_{j}^{-}\right) . v_{j}^{*}$ and $v_{j}^{-}$vectors can indicate that in each criterion which alternatives are the best and the worst option.

By having the maximum and minimum vectors, for each alternative the positive and negative ideal solution $\left(S_{j}^{*}\right.$ and $\left.S_{j}^{-}\right)$can be calculated, resulting in $C_{i}^{*}$ vectors to show the final score of each alternative. Finally, by applying the TOPSIS method equation (eq. 7), the best and the worst alternative can be decided.

Table 3 shows the final decision-making scores for three semiconductor candidates.

Based on the obtained scores, $\mathrm{TiO}_{2}$ is the best choice to investigate in term of bringing the PEC-based $\mathrm{H}_{2}$ production technology from the R\&D level to its prototype level. By a narrow margin, $\mathrm{WO}_{3}$ is the second reasonable option and $\mathrm{BiVO}_{4}$ as the last option among these three semiconductors, is expected to drive the least attention.
However, as a developing semiconductor in PEC technology field, this semi-conductive material is less familiar than two other well-known semiconductors, $\mathrm{TiO}_{2}$ and $\mathrm{WO}_{3}$. Therefore, it is understandable that the survey may results in choosing $\mathrm{BiVO}_{4}$ as the least favourite alternative.

Another considerable aspect about the survey results is the ratio of each alternative score regards to the best alternative in every criterion. As it is shown in Table 4, the scores of some alternatives in some criterion are so close to the maximum that it can be considered almost equal with the chosen alternative. For instance, in case of "study cost" criterion, $\mathrm{WO}_{3}$ is almost as suitable as $\mathrm{TiO}_{2}$. On the other hand, the score attributed to the synthesis simplicity and material availability of $\mathrm{TiO}_{2}$ are so close to that of $\mathrm{WO}_{3}$ that $\mathrm{TiO}_{2}$ can be considered in an equal priority with $\mathrm{WO}_{3}$ in these two criteria. 
Table 3.

TOPSIS decision making results for each alternative semiconductor

\begin{tabular}{cccc}
\hline & \multicolumn{3}{c}{ Semiconductors } \\
\cline { 2 - 4 } & $\mathrm{TiO}_{2}$ & BiVO $_{4}$ & WO $_{3}$ \\
\hline S* & 0.032971 & 0.075806 & 0.04232 \\
S- & 0.073207 & 0.012997 & 0.064795 \\
\hline Topsis (C*) & $\mathbf{0 . 6 8 9 4 7 5}$ & $\mathbf{0 . 1 4 6 3 5 4}$ & $\mathbf{0 . 6 0 4 9 1 3}$ \\
\hline
\end{tabular}

Table 4.

Scores ratio to the best score of each criterion

\begin{tabular}{cccc}
\hline Criteria & \multicolumn{3}{c}{ Semiconductors } \\
\cline { 2 - 4 } & TiO2 & BiVO4 & 0.995455 \\
\hline Study Cost & 1 & 0.663158 & 1 \\
Synthesis Simplicity & 0.962025 & 0.624917 & 1 \\
Facility \& Availability & 0.978355 & 0.535885 & 0.876923 \\
Deposition capability on TCO & 1 & 0.654656 & 0.715385 \\
Modifiability & 1 & 0.773684 & 0.8 \\
Commercialization in H2 Production & 1 & 0.663158 & 0.737288 \\
Physical and Chemical Durability & 1 & 0.758698 & 1 \\
Eco-friendly Fabrication & 0.666667 & 0.786629 & \\
\hline
\end{tabular}

\section{Conclusion}

In this study, by utilizing TOPSIS decision making algorithm the most suitable semiconductor for a PECbased hydrogen generation technology is selected. $\mathrm{TiO}_{2}$, WO3 and BiVO4 are three well-known PEC semiconductors that are selected for comparison based on their diverse advantages. The current Multi Criteria Decision Making (MCDM) study is performed by providing a questionnaire based on eight criteria and three alternatives and ten PEC and hydrogen production experts were asked to fill them. "Study Cost", "Synthesis Simplicity", "Facility \& Availability", "Deposition capability on TCO", "Modifiability", "Commercialization in $\mathrm{H}_{2}$ production", "Physical and Chemical Durability" and "Eco-friendly Fabrication" are the eight criteria that are considered in this evaluation.

As the results show, $\mathrm{TiO}_{2}$ is selected as the best semiconductor in terms of study cost, TCO deposition capability, modifiability, commercialization and durability. On the other hand, $\mathrm{WO}_{3}$ as another well-known PEC semiconductor is chosen as the best option in terms of synthesis simplicity, Facility \& Availability and ecofriendly fabrication. However, based on the survey, BiVO4 could not surpass the two other famous semiconductors in any criterion. In conclusion, $\mathrm{TiO}_{2}$ is selected as the best alternative for energy, money and time investment in order to start a PEC-based hydrogen production project

\section{Acknowledgements}

We want to thank Dr. M.A. Nazari for his useful discussion and valuable support.

\section{References}

Abe, R. (2010). Recent progress on photocatalytic and photoelectrochemical water splitting under visible light irradiation. Journal of Photochemistry and Photobiology C: Photochemistry Reviews, 11(4), 179-209. https://doi.org/10.1016/j.jphotochemrev.2011.02.003

Acar, C., \& Dincer, I. (2016). A review and evaluation of photoelectrode coating materials and methods for photoelectrochemical hydrogen production. International Journal of Hydrogen Energy, 41(19), 7950-7959. https://doi.org/10.1016/j.ijhydene.2015.11.160

Ahmadi, M. H., Alhuyi Nazari, M., Sadeghzadeh, M., Pourfayaz, F., Ghazvini, M., Ming, T., ... \& Sharifpur, M. (2018a). Thermodynamic and economic analysis of performance evaluation of all the thermal power plants: A review. Energy Science \& Engineering. https://doi.org/10.1002/ese 3.223

Ahmadi, M. H., Ghazvini, M., Sadeghzadeh, M., Alhuyi Nazari, M., Kumar, R., Naeimi, A., \& Ming, T. (2018b). Solar power technology for electricity generation: A critical review. Energy Science \& Engineering, 6(5), 340-361. https://doi.org/10.1002/ese3.239

Ahmadi, M. H., Ramezanizadeh, M., Nazari, M. A., Lorenzini, G., Kumar, R., \& Jilte, R. (2018c). Applications of nanofluids in geothermal: A review. Mathematical Modelling of Engineering Problems. 281-285. https://doi.org/10.18280/mmep.050402

Ahmadi, M. H., Banihashem, S. A., Ghazvini, M., \& Sadeghzadeh, M. (2018d). Thermo-economic and exergy assessment and optimization of performance of a hydrogen production system by using geothermal energy. Energy \& Environment, 29(8), 1373-1392. https://doi.org/10.1177/0958305X18779573

Ali, H., Ismail, N., Amin, M. S., \& Mekewi, M. (2018). Decoration of vertically aligned TiO 2 nanotube arrays with WO 3 particles for hydrogen fuel production. Frontiers in Energy, 110. https://doi.org/10.1007/s11708-018-0547-1

Amekan, Y., Wangi, P., Ayu, D. S., Cahyanto, M. N., \& Widada, J. (2018). Effect of Different Inoculum Combination on Biohydrogen Production from Melon Fruit Waste. International Journal of Renewable Energy Development, 7(2). http:// doi.org/10.14710/ijred.7.2.101-109

Bp, G. (2018). Bp Statistical Review of World Energy. 2018. https://www. bp. com/en/global/corporate/energyeconomics/statistical-review-of-world-energy. html (accessed on 4 September 2018). Sustainability, 10(3195), 17. 
Chang, P. L., \& Chen, Y. C. (1994). A fuzzy multi-criteria decision making method for technology transfer strategy selection in biotechnology. Fuzzy Sets and Systems, 63(2), 131-139. https://doi.org/10.1016/0165-0114(94)90344-1

Chen, X., Xiong, J., Shi, J., Xia, S., Gui, S., \& Shangguan, W. (2018). Roles of various Ni species on TiO 2 in enhancing photocatalytic H 2 evolution. Frontiers in Energy, 1-7. http:// doi.org/10.1007/s11708-018-0585-8

Chen, X., \& Shangguan, W. (2013). Hydrogen production from water splitting on CdS-based photocatalysts using solar light. Frontiers in Energy, 7(1), 111-118. http:// doi.org/10.1007/s11708-012-0228-4

Daghrir, R., Drogui, P., \& Robert, D. (2013). Modified TiO2 for environmental photocatalytic applications: a review. Industrial \& Engineering Chemistry Research, 52(10), 35813599. http:// doi.org/10.1021/ie303468t

Dehghani Madvar, M., Alhuyi Nazari, M., Tabe Arjmand, J., Aslani, A., Ghasempour, R., \& Ahmadi, M. H. (2018). Analysis of stakeholder roles and the challenges of solar energy utilization in Iran. International Journal of Low-Carbon Technologies, 13(4),

438-451. https://doi.org/10.1093/ijlct/cty044

Eilat, H., Golany, B., \& Shtub, A. (2008). R\&D project evaluation: An integrated DEA and balanced scorecard approach. Omega, 36(5), 895-912. https://doi.org/10.1016/j.omega.2006.05.002

El Amine, M., Pailhes, J., \& Perry, N. (2014). Comparison of different Multiple-criteria decision analysis methods in the context of conceptual design: application to the development of a solar collector structure. Proceedings of Joint Conference on Mechanical, Design Engineering, Advanced Manufacturing, Toulouse, France,, Jun 2014, France. pp.1-6. ffhal-00987264

Ghasempour, R., Nazari, M. A., Ebrahimi, M., Ahmadi, M. H., \& Hadiyanto, H. (2017). MCDM Approach for Selecting Solar Plants Site and Technology: A Review. International Journal of Renewable Energy Development, 8(1), 15-25.

Ghoujdi, I. E., Hadiannasab, H., Bidi, M., Naeimi, A., Ahmadi, M. H., Nazari, M. A., \& Ming, T. (2018). Multiobjective optimization design of the solar field and reverse osmosis system with preheating feed water using Genetic algorithm. Energy Science \& Engineering, 6(6), 624-642. https://doi.org/10.1002/ese3.237

Haghighi Bardineh, Y., Mohamadian, F., Ahmadi, M. H., \& Akbarianrad, N. (2018). Medical and dental applications of renewable energy systems. International Journal of LowCarbon Technologies, 13(4), 320-326. https://doi.org/10.1093/ijlct/cty040

Handayani, N. A., \& Ariyanti, D. (2012). Potency of solar energy applications in Indonesia. International Journal of Renewable Energy Development, 1(2), 33-38. https://doi.org/10.14710/ijred.1.2.33-38

IRENA (2018), Hydrogen from renewable power: Technology outlook for the energy transition, International Renewable Energy Agency, Abu Dhabi.

Junior, F. R. L., Osiro, L., \& Carpinetti, L. C. R. (2014). A comparison between Fuzzy AHP and Fuzzy TOPSIS methods to supplier selection. Applied Soft Computing, 21, 194-209.

Kaloi, G. S., Wang, J., Baloch, M. H., \& Tahir, S. (2017). Wind Energy Potential at Badin and Pasni Costal Line of Pakistan. International Journal of Renewable Energy Development, 6(2). https://doi.org/10.14710/ijred.6.2.103-110

Kanoglu, M., Yilmaz, C., \& Abusoglu, A. (2016). Geothermal Energy Use in Hydrogen Production. Journal of Thermal Engineering, 2(2), 699-708. http://doi.org/10.18186/jte.58324

Khouja, M. (1995). The use of data envelopment analysis for technology selection. Computers \& Industrial Engineering, 28(1), 123-132. https://doi.org/10.1016/0360-8352(94)00032-I

Liu, S., Yu, J., \& Jaroniec, M. (2011). Anatase TiO2 with dominant high-energy $\{001\}$ facets: synthesis, properties, and applications. Chemistry of Materials, 23(18), 4085-4093. https://doi.org/10.1021/cm200597m

Madhusudan, P., Kumar, M. V., Ishigaki, T., Toda, K., Uematsu, K., \& Sato, M. (2013). Hydrothermal synthesis of meso/macroporous BiVO 4 hierarchical particles and their photocatalytic degradation properties under visible light irradiation. Environmental Science and Pollution Research, 20(9), 6638-6645. https://doi.org/10.1007/s11356-013-1694-x

Menges, R., \& Pfaffenberger, W. (2015). Promotion of Renewable Energy Sources in the European Union. International Journal of Renewable Energy Development, 4(3). http://doi.org/10.14710/ijred.4.3.171-180

Mills, A., \& Le Hunte, S. (1997). An overview of semiconductor photocatalysis. Journal of photochemistry and photobiology A: Chemistry, 108(1), 1-35. https://doi.org/10.1016/S10106030(97)00118-4

Moniz, S. J., Shevlin, S. A., Martin, D. J., Guo, Z. X., \& Tang, J. (2015). Visible-light driven heterojunction photocatalysts for water splitting-a critical review. Energy \& Environmental Science, 8(3), 731-759. https://doi.org/10.1039/C4EE03271C

Muppala, S., Manickam, B., \& Dinkelacker, F. (2015). A Comparative Study of Different Reaction Models for Turbulent Methane/Hydrogen/Air Combustion. Journal of Thermal Engineering, 1(5), 367-380. http:// doi.org/10.18186/jte.60394

Nazari, M. A., Aslani, A., \& Ghasempour, R. (2018). Analysis of solar farm site selection based on TOPSIS approach. International Journal of Social Ecology and Sustainable Development (IJSESD), 9(1), 12-25. http:// doi.org/10.4018/IJSESD.2018010102

Nazemzadegan, M. R., Kasaeian, A., Toghyani, S., Ahmadi, M. H., Saidur, R., \& Ming, T. (2017). Multi-objective optimization in a finite time thermodynamic method for dish-Stirling by branch and bound method and MOPSO algorithm. Frontiers in Energy, 1-17. https://doi.org/10.1007/s11708-018-0548-0

Ni, M., Leung, M. K., Leung, D. Y., \& Sumathy, K. (2007). A review and recent developments in photocatalytic watersplitting using TiO2 for hydrogen production. Renewable and Sustainable Energy Reviews, 11(3), 401-425. https://doi.org/10.1016/j.rser.2005.01.009

Poh, K. L., Ang, B. W., \& Bai, F. (2001). A comparative analysis of R\&D project evaluation methods. $R \& D$ Management, 31(1), 63-75. https://doi.org/10.1111/1467-9310.00197

Ramezanizadeh, M., Nazari, M. A., Ahmadi, M. H., \& Açıkkalp, E. (2018a). Application of nanofluids in thermosyphons: A review. Journal of Molecular Liquids. https://doi.org/10.1016/j.molliq.2018.09.101

Ramezanizadeh, M., Nazari, M. A., Ahmadi, M. H., Lorenzini, G., Kumar, R., \& Jilte, R. (2018b). A review on the solar applications of thermosyphons. Mathematical Modelling of Engineering Problems. 5(4), 275-280. https://doi.org/10.18280/mmep.050401

Talukdar, K. (2017). Modeling and Analysis of Solar Photovoltaic Assisted Electrolyzer-Polymer Electrolyte Membrane Fuel Cell For Running a Hospital in Remote Area in Kolkata, India. International Journal of Renewable Energy Development, 6(2), 181. http:// doi.org/10.14710/ijred.6.2.181191

Tscheikner-Gratl, F., Egger, P., Rauch, W., \& Kleidorfer, M. (2017). Comparison of multi-criteria decision support methods for integrated rehabilitation prioritization. Water, 9(2), 68. https://doi.org/10.3390/w9020068

U.S. Department of Energy [DOE]. (2018). DOE 2020 Targets by Application, EERE, FCTO, Fuel Cells Program Area, 2017 Annual Merit Review and Peer Evaluation Meeting. https://www.hydrogen.energy.gov/annual_review17_report.h tml. (June 5-9 2017), 1-5.

U.S. Department of Energy [DOE]. (2015). DOE Fuel Cell Technologies Office Multi-Year Research, Development, and Demonstration Plan, chapter (3) Hydrogen Production, 11007, 1-44.

U.S. Department of Energy [DOE]. (2018). DOE Technical Targets for Hydrogen Production from Photoelectrochemical Water Splitting. https://www.energy.gov/eere/fuelcells/doetechnical-targets-hydrogen-production-photoelectrochemicalwater-splitting. 1-6.

Vafaeipour, M., Zolfani, S. H., Varzandeh, M. H. M., Derakhti, A., \& Eshkalag, M. K. (2014). Assessment of regions priority for implementation of solar projects in Iran: New application of a 
hybrid multi-criteria decision making approach. Energy Conversion and Management, 86, 653-663. https://doi.org/10.1016/j.enconman.2014.05.083

Venkatesan, R., Velumani, S., \& Kassiba, A. (2012). Mechanochemical synthesis of nanostructured BiVO4 and investigations of related features. Materials Chemistry and Physics, 135(2-3), 842-848. https://doi.org/10.1016/j.matchemphys.2012.05.068

Victório, C. J. M., Costa, H. G., \& Souza, C. G. D. (2015). Modeling selection criteria of R\&D projects for awarding direct subsidies to the private sector. Science and Public Policy, 43(2), 275-287. https://doi.org/10.1093/scipol/scu088

Wang, S. H., Chang, S. P., Williams, P., Koo, B., \& Qu, Y. R. (2015). Using Balanced Scorecard for Sustainable Designcentered Manufacturing. Procedia Manufacturing, 1, 181192. https://doi.org/10.1016/j.promfg.2015.09.084

Wang, W. P., \& Tang, M. C. (2015). A multi-criteria assessment for R\&D innovation with fuzzy computing with words. In Modelling, Computation and Optimization in Information Systems and Management Sciences (pp. 3-14). Springer, Cham. https://doi.org/10.1007/978-3-319-18167-7_1
Watson, J. J., \& Hudson, M. D. (2015). Regional Scale wind farm and solar farm suitability assessment using GIS-assisted multi-criteria evaluation. Landscape and Urban Planning, 138, 20-31. https://doi.org/10.1016/j.landurbplan.2015.02.001

Xia, D., Yu, Q., Gao, Q., \& Cheng, G. (2017). Sustainable technology selection decision-making model for enterprise in supply chain: Based on a modified strategic balanced scorecard. Journal of cleaner production, 141, 1337-1348. https://doi.org/10.1016/j.jclepro.2016.09.083

Yourey, J. E. (2014). Photoelectrochemical and Photocatalytic Water Oxidation using Metal Oxides. $\mathrm{PhD}$ thesis, University of Michigan.

Zaleska, A. (2008). Doped-TiO2: a review. Recent patents on engineering, $2(3), \quad 157-164$. https://doi.org/10.2174/187221208786306289

Zhao, H., \& Li, N. (2015). Evaluating the performance of thermal power enterprises using sustainability balanced scorecard, fuzzy Delphic and hybrid multi-criteria decision making approaches for sustainability. Journal of Cleaner Production, 108, 569-582. https://doi.org/10.1016/j.jclepro.2015.07.141 